\title{
Relações intergovernamentais na assistência técnica e financeira da União para a educação básica: tensões entre a regulação federal e a autonomia dos governos subnacionais
}

\author{
Cacilda Rodrigues Cavalcanti ${ }^{1}$
}

\begin{abstract}
Resumo: $\mathrm{O}$ artigo aborda as relações intergovernamentais na assistência técnica e financeira da União aos entes federados subnacionais para a oferta e manutenção da educação básica, tendo como referência analítica as tensões próprias do federalismo entre a autonomia e interdependência entre os entes federados. O tema é desenvolvido a partir da análise de conteúdo das resoluções do FNDE que regulamentaram as ações de assistência técnica e financeira no período de 2004 a 2014. Apresentam-se evidências empíricas acerca da indução da agenda educacional dos governos subnacionais por parte do governo federal e problematizações acerca das tensões que essa política estabelece entre a regulação federal e a autonomia dos governos subnacionais na formulação e implementação das políticas educacionais.

Palavras-chave: relações intergovernamentais, educação básica, assistência da união, federalismo

\section{Intergovernmental relations in the technical and financial assistance from the Federal Government to basic education: tensions between federal} regulation and the autonomy of subnational governments
\end{abstract}

\begin{abstract}
The paper addresses intergovernmental relations in the technical and financial assistance from the federal government to the subnational federating entities for the provision and maintenance of basic education, having as analytical reference the intrinsic federalism tensions between autonomy and interdependence among the federating entities. The theme is developed from the content analysis of the FNDE [National Fund for Education Development] resolutions which regulated the actions of technical and financial assistance from 2004 to 2014. Empirical evidence concerning the induction of the subnational governments educational agenda by the federal government is presented, as well as problematizations related to the tensions that this policy establishes between the federal regulation and the autonomy of subnational governments in the formulation and implementation of educational policies.

Keywords: Intergovernmental relations; Basic Education; Federal governmental assistance; Federalism.

${ }^{1}$ Professora do Departamento de Educação II da Universidade Federal do Maranhão; Doutora em Educação pela Universidade Federal de Minas Gerais. E-mail: cavalcanticacilda@gmail.com.
\end{abstract}

\begin{tabular}{|l|l|l|l|l|} 
Textura & Canoas & v. 19 n.40 & p.7-35 & maio/ago. 2017 \\
\hline
\end{tabular}




\section{INTRODUÇ̃̃O}

O modelo de divisão de responsabilidades e recursos entre os entes federados para a garantia do direito à educação adotado na Constituição Federal de 1988, conduziu, gradativamente, à adoção de diversos arranjos federativos no campo da educação básica, suscitando debates, estudos e pesquisas sobre as relações intergovernamentais no campo das políticas educacionais.

Um breve panorama das iniciativas e debates recentes no âmbito das políticas públicas de educação e, mais especificamente, no campo do financiamento da educação básica, deixam evidente a centralidade do debate federativo que tem marcado as políticas educacionais, tanto no que se refere aos marcos legais quanto à formulação, implementação e gestão das políticas educacionais.

A abordagem federativa, em especial no que diz respeito à função supletiva da União na perspectiva de um padrão de qualidade e de maior equalização na oferta da educação básica, ocupou importante espaço nos debates que marcaram o processo de elaboração e aprovação do Fundo de Manutenção e Desenvolvimento da Educação Básica e de Valorização dos Profissionais da Educação (Fundeb), resultando em um maior aporte de recursos da União para a complementação do fundo naqueles estados que não alcançam o valor mínimo nacional estabelecido, ainda que com limites tanto no que se refere à qualidade quanto à equidade. Estudos como os de Pinto (2007, 2012, 2015), Martins (2009) e Araújo (2013) têm analisado e problematizado esta temática.

A ação supletiva e redistributiva da União, o regime de colaboração e o Sistema Nacional de Educação constituíram importantes temas que envolvem as relações intergovernamentais e que movimentaram a agenda das Conferências Nacionais de Educação de 2010 e 2014, dando a tônica dos debates no processo de elaboração e aprovação do novo Plano Nacional de Educação (2014-2024), cujas metas e estratégias expressam bem as tensões federativas que estão em curso no campo do financiamento da educação básica.

As tensões são intrínsecas ao modo de organização do Estado em um sistema federativo. Porém, estas podem ser potencializadas e gerar conflitos diversos, tendo em vista as características sociais, econômicas e políticas da federação e o seu desenho federativo. No caso específico do financiamento da 
educação básica brasileira, as muitas tensões que têm se manifestado nas duas últimas décadas entre os entes federados têm suas bases na relação entre o modelo de divisão das responsabilidades pela oferta e manutenção da educação pública e o modelo de divisão dos recursos financeiros para cumprir tais responsabilidades, atribuídas pela Constituição de 1988. Desde então, diversos arranjos vêm sendo desenvolvidos, produzindo uma dinâmica federativa em permanente tensão, própria da necessária compatibilização entre autonomia e interdependência que caracteriza os sistemas federais.

É nesse contexto, marcado por uma intensa dinâmica de arranjos federativos, que se insere o presente artigo, cujo foco é dirigido para a assistência técnica e financeira da União prevista constitucionalmente e reiterada pela LDB n ${ }^{\circ} 9.394 / 1996$, em especial, no que tange aos programas de transferências legais e voluntárias sob a gestão do Fundo Nacional de Desenvolvimento da Educação (FNDE). Três aspectos influenciaram a escolha do recorte do objeto de estudo para os programas de assistência técnica e financeira.

Primeiro, os programas de assistência legal e voluntária guardam a singularidade de uma tensão, que envolve a capacidade decisória da União quanto ao formato e destino dos recursos, em especial, mas não exclusivamente, dos programas de assistência voluntária ${ }^{2}$, de um lado, e a autonomia dos entes federados subnacionais para formular e implementar suas políticas educacionais, de outro.

Segundo, a definição de critérios e procedimentos para tais transferências e a forma de organização destas em um conjunto diversificado de programas de assistência técnica e financeira indicam a formulação de uma agenda do governo federal para a política de educação básica a ser implementada em todo território nacional, o que expressa uma tensão entre a assistência da União e a autonomia dos entes federados subnacionais.

Terceiro, a regulamentação e a gestão de tais transferências pelo FNDE, que na condição de autarquia do $\mathrm{MEC}$, se constitui em uma arena mais insulada a processos de negociação entre governos e de participação social, sinalizam para a formulação de políticas sem processos de coordenação federativa.

\footnotetext{
${ }^{2}$ Embora os programas de assistência legal tenham seus escopos definidos por lei federal, estes não estão totalmente imunes à interferência da União (MEC/FNDE), uma vez que a própria lei que os instituiu delegou ao MEC e/ou ao FNDE a definição de seus aspectos procedimentais.
} 


\section{RELAÇÕES INTERGOVERNAMENTAIS: AS TENSÕES ENTRE NEGOCIAÇÃO, COOPERAÇÃO E COORDENAÇÃO NAS FEDERAÇÕES}

As relações intergovernamentais constituem uma importante dimensão dos estudos em torno do federalismo, sobretudo, na perspectiva do federalismo cooperativo, uma vez que é por meio delas que se estabelece a dinâmica federativa própria de cada sistema federal.

De acordo com Elazar (1991), tem havido uma discussão entre estudiosos do federalismo acerca de "relações intergovernamentais" como um termo mais apropriado ao estudo dos sistemas federais. O autor identifica dois elementos envolvidos na emergência dessa nova terminologia.

O primeiro é o surgimento de estudos da administração dos sistemas federais de forma separada das dimensões legais e constitucionais do federalismo, ocorridos desde os anos de 1930. Estes tendiam a focar sobre relações intergovernamentais como um termo útil para a definição de objetos dessas investigações e também para distingui-lo do que veio ser considerado, cada vez mais, como uma investigação árida em doutrinas constitucionais e legais que ignoravam a maioria das realidades da política e da administração que foram se tornando importantes em um contexto de expansão dos governos. O outro elemento é a influência behaviorista na ciência política ocorrida nas décadas de 1950 e 1960, que buscava, entre outras coisas, se desfazer de "terminologias tradicionais" (das quais o federalismo foi considerado um excelente exemplo) para terminologias mais "científicas", adequadas a uma ciência da política, na qual o termo "relações intergovernamentais" era apresentado como um conceito de maior precisão. (ELAZAR, 1991)

O uso do termo relações intergovernamentais como um substituto de federalismo ou como um fenômeno universal, a ser encontrado onde quer que dois ou mais governos interagem na elaboração e execução de políticas, segundo Elazar (1991, p.16), decorre do uso americano restrito do termo federalismo, resultante da experiência histórica dos EUA, que por conta de seus fundamentos de federalismo, entende que cada unidade governamental federal, estadual e local - responde a determinados critérios objetivos para ser um governo próprio. Para o modelo norte-americano, segundo o autor, esta interpretação é totalmente adequada porque a teoria federal norte-americana afirma que a autoridade e o poder político residem no povo, que delega poderes, por meio de dispositivos constitucionais, para diferentes governos que servem a diferentes arenas para diferentes fins. 
Portanto, relações intergovernamentais não constituem, na concepção de Elazar, uma característica específica das federações. Federalismo e relações intergovernamentais são conceitos em interação, mas que dizem respeito a aspectos ou dimensões diferentes.

Federalismo é o termo genérico para o que pode ser referido como relações de regras compartilhadas e regras próprias; "As relações intergovernamentais" têm a ver com determinadas formas e meios de operacionalizar um sistema de governo [...] que envolvem relações extensas e contínuas entre os governos federal, estaduais e locais ou qualquer combinação disso. ${ }^{3}$ (ELAZAR,1991, p.16, tradução nossa).

Federalismo é, desse modo, um conceito a priori e mais abrangente, do qual o conceito de relações intergovernamentais é subsidiário. Visto assim, "relações intergovernamentais" constitui um termo técnico de grande utilidade para explorar processos dentro de sistemas políticos particulares, especialmente (mas não exclusivamente), os federais, e de forma mais eficaz, embora não exclusivamente, aqueles que começam com uma visão federalista, em vez de uma visão estadista de soberania. No caso destes últimos, o termo relações intergovernamentais - contrariamente aos propósitos de neutralidade científica que conduziram a uma não normatividade do termo nos Estados Unidos - pode ganhar conotações bastante normativas porque, de fato, define e redefine a natureza da autoridade no seio do sistema político. Desde que se considerem as implicações normativas do termo "relações intergovernamentais", ele também pode ser empiricamente útil para descrever o que é, afinal, um fenômeno universal de particular importância na nossa época, de estruturas, relações e processos governamentais de alta complexidade. Em tais casos, a utilização subsidiária do termo "relações intergovernamentais" pode reforçar o uso do termo raiz "federalismo" na conceituação da ordem política, bem como para a descrição e análise da política. (ELAZAR, 1991, p.18)

Essa perspectiva conceitual de relações intergovernamentais, de caráter operacional, é tomada por Watts (2008) em seus estudos comparados de

${ }^{3}$ Tradução livre de Elazar (1991, p.16): "Federalism is the generic term for what may be referred to as self-rule/shared-rule relationships; 'intergovernmental relations' has to do with particular ways and means of operationalizing a system of governmentin [...] that involve extensive and continuing relations among the federal, state, and local governments or any combination there of." 
sistemas federais. Para o autor, em tais sistemas, as relações intergovernamentais, ainda que em graus diferentes, envolvem inevitáveis processos de negociação, cooperação, coordenação entre os governos, já que sobreposição e interdependência no exercício do poder pelos diferentes níveis de governo são próprias de sistemas federais, sobretudo, no federalismo cooperativo.

As relações intergovernamentais envolvem mecanismos formais (institucionais) e informais que estabelecem processos de negociação, cooperação e coordenação entre os governos. Mecanismos formais incluem tanto o legislativo quanto as instituições e arenas do executivo (ministérios, departamentos, agências, programas governamentais). Porém, como ressalta Watts (2008), na maioria das federações, em especial, em federações parlamentaristas, tem prevalecido um federalismo executivo, isto é, as relações intergovernamentais têm sido amplamente determinadas pelas instituições do executivo (ministérios e seus órgãos oficiais). Nessas federações, cada vez mais, o governo federal tem estabelecido órgãos especializados para coordenar sua relação com os outros níveis de governo. Mecanismo informais envolvem, sobretudo, os processos de comunicação e interação entres os funcionários dessas instituições - elaboradores e executores de políticas públicas - os quais, embora ocupem pouco espaço nos estudos e pesquisas, têm forte impacto nas relações que se estabelecem entre os governos, especialmente, naquelas federações onde as relações intergovernamentais são marcadas por clientelismo e poucos mecanismos de accountability.

Mecanismos e arenas de coordenação intergovernamental constituem, na avaliação de Watts (2008), uma marca recente das federações, nas quais tem sido, cada vez mais comum, o estabelecimento de arenas colegiadas, tanto gerais, quanto para áreas específicas de políticas, tais como saúde, educação e meio ambiente, envolvendo algumas vezes o legislativo, e outras vezes, apenas o executivo dos diversos níveis de governo.

O movimento nessa direção, abordado por Elazar (1991) como um movimento para a tomada de decisão colegiada, foi impulsionado pelos processos de descentralização fiscal e política ocorridos nas duas últimas décadas do século passado, que envolveram, principalmente, os órgãos formuladores de políticas tanto do governo nacional quanto dos governos das unidades constituintes. $\mathrm{O}$ autor destaca duas tendências nesse processo no que diz respeito aos órgãos formuladores de políticas: 1) um movimento geral para tomada de decisão colegiada; e (2) um movimento em direção ao 
estabelecimento das autoridades para propósitos específicos e de organismos mistos público-privado como formuladores de políticas e dispositivos de implementação. (ELAZAR, 1991, p. 207).

$\mathrm{Na}$ análise deste autor, esse movimento tardio deve-se, em parte, ao modelo de administração hierarquizado que prevaleceu nas federações, assentado na ideia de que as burocracias realmente funcionavam de acordo com o modelo hierárquico, no qual o poder deveria ser controlado e melhor coordenado pela parte superior ou pelo centro. Assim, a ideia de instituições administrativamente separadas ainda tem sido a norma em muitas federações, o que torna complexos os processos de coordenação intergovernamental, de forma que os processos de partilha na tomada de decisão, formulação e execução de políticas têm sido manifestados, segundo Elazar (1991), principalmente, por meio de ações distintas por parte de cada instituição em particular, compreendendo uma série de trocas e articulações, conforme as características e possibilidades das instituições e dos pontos de interesse que as envolvem.

Considerada a necessária rigidez das Constituições como asseguradora do pacto federal, mecanismos e arenas de coordenação intergovernamental (federativa) tornam-se necessários para garantir o grau de flexibilidade e cooperação nas áreas de competências compartilhadas e podem ser um contraponto à competição maléfica, a exemplo da guerra fiscal que marca algumas federações. Além do importante papel nas diretrizes e concepções de políticas nacionais, tais arenas têm sido um importante espaço de ajuste no que se refere a procedimentos de repartição de recursos.

Por meio de seus estudos comparados, Watts (2008) identifica quatro padrões de arranjos federais para coordenação intergovernamental no que se refere à repartição de recursos: 1) comissão de experts que tem a função primária de apresentar estudos e diretrizes para a determinação da fórmula redistributiva, como as existentes na Austrália, Índia, África do Sul e Nigéria; 2) conselho intergovernamental composto de representação do governo federal e das unidades constituintes, do qual Malásia e Paquistão são bons exemplos; 3) legislativo federal, que prevalece na Alemanha, Estados Unidos, Áustria, Suíça, Bélgica, Brasil e Argentina; 4) governo federal com a representação dos governos subnacionais, que é o padrão canadense. Porém, o autor chama atenção para o fato de que cada padrão é o prevalecente, existindo sempre outros arranjos que podem desempenhar papel importante, em determinados contextos e questões. 
Watts (2008) observa que federações, em geral, são caracterizadas, simultaneamente, por elementos de cooperação, colaboração, coordenação, competição e conflitos, coexistindo e mudando o tempo todo, pois são processos próprios da dinâmica das relações intergovernamentais na operacionalização da ideia federativa. Contudo, as características e a extensão desses processos variam amplamente, de acordo com fatores históricos, geográficos, políticos e econômicos de cada sistema político federal, como também de acordo com as regras constitucionais e as circunstâncias específicas das políticas em foco.

Assim, nos sistemas federais a necessária compatibilidade de interdependência e autonomia exige que governo central e governos subnacionais compartilhem não apenas as competências relativas à execução das políticas públicas, mas também o poder da tomada de decisões sobre elas. Assim, Biela, Annika e Kaiser (2013) e Arretche (2012) argumentam acerca da necessidade de se distinguir conceitualmente entre a autoridade para decidir (policy decision-making) e a autoridade para executar (policy making) no estudo das políticas sociais. Para os primeiros autores, esses dois processos constituem dois diferentes estágios do processo político que têm implicações diferentes para o federalismo e para a descentralização. Enquanto o federalismo tende a influenciar mais o processo de tomada de decisão e formulação das políticas, a descentralização tende a influenciar mais o processo de implementação.

Arretche (2012) analisa policy decision-making e policy making como dimensões próprias do conceito de federalismo formulado por Elazar (1991) como a combinação de share-rule and self-rule portanto, como processos da dinâmica centralização/descentralização em uma federação, que é uma forma de Estado não-centralizada. A distinção entre essas duas dimensões da divisão da autoridade nas federações é, segundo Arretche (2012), mais importante para a análise das políticas públicas que a distinção binária entre Estado federativo e Estado unitário. Além disso, essa distinção possibilita também duas outras importantes distinções conceituais para a análise dos processos de formulação e implementação de políticas em estados federativos: a distinção entre União e executivo federal e a distinção entre os conceitos de descentralização política, fiscal e de competências.

Essas duas ordens de distinções têm relevantes consequências analíticas, pois com frequência, análises sobre o federalismo e a descentralização assumem que evidências empíricas sobre uma dimensão podem ser adequadamente tomadas como proxy da 
outra. Essa inferência, contudo, não se justifica se esses conceitos referem-se a dimensões qualitativamente distintas da distribuição da autoridade nos estados nacionais. (ARRETCHE, 2012, p.146).

Tais distinções são importantes para a compreensão das relações intergovernamentais e para uma análise mais adequada dos processos de centralização e descentralização nas federações, pois embora governos subnacionais possam ter importantes funções na provisão dos serviços públicos, o exercício destas depende do poder que dispõem para decidir sobre tais serviços, bem como do poder de decisão e regulação concentrado nas mãos do governo federal, principalmente no que se refere à arrecadação tributária e à alocação dos gastos.

Arretche $(2004,2005,2012)$ e Tsebelis (1995) mostram em seus estudos que em sistemas federais o governo central sempre dispõe, em maior ou menor grau, de mecanismos para influenciar a agenda dos governos subnacionais. $\mathrm{Na}$ análise de Arretche, isto pode ocorrer tanto por meio da regulação federal, decorrente da função de coordenação nacional dessa esfera governamental, quanto pelo desenho das políticas sociais sob as quais o governo tem autoridade decisória.

Tsebelis mostra ainda, em sua teoria do veto players ${ }^{4}$, que há diversas possibilidades de o governo federal escolher procedimentos de política voltados para reduzir o número de veto players envolvidos, controlar as dimensões de negociações e assim influenciar a agenda dos governos subnacionais.

Portanto, pode-se observar que os debates e análises acerca das relações intergovernamentais são de fundamental importância para o estudo das políticas públicas no federalismo, principalmente quando focamos nas tensões que marcam tais relações, as quais não podem ser apreendidas tomando-se apenas o desenho constitucional, mas precisam adentrar aos aspectos procedimentais das políticas que envolvem governo nacional e governos subnacionais.

No Estado federativo, as relações intergovernamentais no campo das políticas sociais, entre elas, a educação, se estabelecem tanto por meio do

\footnotetext{
${ }^{4}$ Um veto player é um ator individual ou coletivo, institucionais ou partidários cuja concordância é
} necessária para que se tome uma decisão política. 
poder legislativo quanto do poder executivo. No legislativo federal, as relações intergovernamentais são amplamente definidas pela dinâmica dos partidos políticos e das agendas de grupos e classes sociais em disputa. No executivo, as relações intergovernamentais são amplamente influenciadas pelas políticas sociais formuladas e coordenadas pelo governo federal, podendo, em alguns contextos e em algumas políticas, serem mais ou menos colaborativas.

Sendo assim, as políticas educacionais formuladas e coordenadas pelo governo federal constituem objeto estratégico para a análise das relações intergovernamentais no campo da política educacional, em especial no campo da assistência da União aos entes federados subnacionais. No campo da educação, estas são determinadas, tanto pelos marcos regulatórios nacionais, que definem, entre outros aspectos, as responsabilidades de cada governo e a necessidade de ações colaborativas entre eles para a garantia do direito à educação, quanto pela dinâmica e circunstâncias da política educacional em cada momento histórico. Na seção seguinte, analisaremos a política de assistência técnica e financeira da União na oferta e manutenção da educação que se configurou a partir de 2004, com o objetivo de trazer ao debate as tensões entre autonomia e interdependência entre as esferas governamentais no processo de formulação e implementação dessas políticas.

\section{A POLÍTICA DE ASSISTÊNCIA TÉCNICA E FINANCEIRA DA UNIÃO PARA A EDUCAÇÃO BÁSICA A PARTIR DE 2004}

Em conformidade com a Constituição Federal de 1998, a LDB ${ }^{\circ}$ 9.394/96, definiu como uma das competências privativas da União, a função de "coordenação da política nacional de educação, articulando os diferentes níveis e sistemas e exercendo função normativa, redistributiva e supletiva em relação às demais instâncias educacionais". ( $\left(1^{\circ}\right.$, Art. $\left.8^{\circ}\right)$. Tais funções são definidas, no âmbito da lei (no Art. $9^{\circ}$ ) em termos de: a) elaboração do Plano Nacional de Educação, em colaboração com os Estados, o Distrito Federal e os Municípios; b) assistência técnica e financeira aos Estados, ao Distrito Federal e aos Municípios para o desenvolvimento de seus sistemas de ensino e o atendimento à escolaridade obrigatória; c) estabelecimento de diretrizes curriculares para a educação básica; d) coleta, análise e disseminação de informações sobre a educação; e) avaliação do rendimento escolar no ensino fundamental, médio e superior, em colaboração com os sistemas de ensino, objetivando a definição de prioridades e a melhoria da qualidade do ensino.

Assim, a autonomia dos Estados e Municípios na organização e gestão dos seus sistemas de ensino é balizada pela função da União de coordenação 
da política nacional de educação, que estabelece uma relação de interdependência entre os sistemas de ensino, mas não de subordinação. Tal aspecto ganhará relevância a partir de meados dos anos 2000, como uma ação mais efetiva da União no desenvolvimento de sua função coordenadora da política nacional de educação e de assistência técnica e financeira aos governos subnacionais na oferta da educação básica.

Ao realizar a sua função de assistência técnica e financeira, a União não apenas transfere recursos financeiros para os demais entes, mas também regulamenta seus fins, sua forma e seus procedimentos, configurando modelos de políticas a serem implementados pelos estados e municípios. Por outro lado, a função redistributiva e supletiva da União envolve também a ação normativa, o que lhe garante a autoridade decisória sobre a regulamentação de recursos e políticas. Portanto, a regulamentação da educação básica por parte da União ocorre tanto por meio da elaboração de marcos regulatórios da política nacional de educação (planejamento, currículo, avaliação) quanto por meio dos atos normativos que disciplinam sua assistência técnica e financeira para os entes federados no campo da educação básica.

Nesta seção, pretende-se, por meio da análise do conteúdo das resoluções do FNDE, caracterizar a política de assistência técnica e financeira da União para a educação básica que vem se estabelecendo desde 2004. Diferentemente das transferências constitucionais, que já são regulamentadas constitucionalmente, as transferências legais e, principalmente, as voluntárias são objetos de intensa normatização pelo governo federal e, por isso, constituem-se em base de dados normativa privilegiada para a compreensão da política de assistência técnica e financeira da União na oferta e manutenção da educação básica e como essa ação influencia a agenda dos governos subnacionais para a implementação de uma política nacional de educação básica projetada e administrada pelo MEC.

A assistência técnica e financeira da União para a educação básica vem sendo desenvolvida, principalmente a partir de 2004, por meio de programas de assistência técnica e financeira, que envolvem Programas de Assistência Legal (PAL) e os Programas de Assistência Voluntária (PAV), e ambos são objetos de regulamentação no âmbito do MEC/FNDE. Ainda que as transferências legais da União sejam amparadas por leis federais que definem seu escopo, forma de transferência, beneficiários e órgãos responsáveis pela sua gestão, estas também são objetos de regulamentação, em seus aspectos 
procedimentais, no interior do FNDE, conforme previsto nas próprias leis que as instituíram 5 .

No período analisado (1999 a 2014), as transferências da União para a educação básica foram objeto de intensa regulamentação no âmbito do FNDE. Por meio de levantamento junto à base de legislação do FNDE foram identificadas 681 resoluções que regulamentaram os programas de assistência técnica e financeira da União para a educação básica brasileira no período estudado. Deste total, 526 resoluções tiveram seu conteúdo analisado, uma vez que 139 resoluções apenas fizeram alterações pontuais em resoluções anteriores ou apenas divulgam lista de projetos aprovados ou municípios contemplados e 16 não estão disponíveis no banco de legislação do FNDE.

Para identificar o modelo de assistência da União para a educação básica e reunir elementos para análise das tensões entre autonomia dos governos subnacionais e a regulação federal, focaremos nossa análise em quatro aspectos: a dinâmica de organização da assistência em forma de programas; as formas de adesão dos governos subnacionais; as formas de transferência dos recursos; e a coordenação federativa nesses programas.

A organização da assistência da União por meio de programas passou a ser ampliada a partir de meados da década de 1990 e aumentou, consideravelmente, a partir de 2004, tonando-se desde então objeto de intensa regulamentação no âmbito do FNDE. Até 2002 havia 24 programas de assistência da União aos governos subnacionais. Ao longo do governo Lula, foram extintos ou reestruturados 14 desses programas e criados mais 22 novos programas, que somados a mais 11 programas criados no governo Dilma, totalizam em 43 programas em vigência atualmente.

Observa-se que, com exceção do Programa Nacional de Educação Ambiental (PRONEA), todos os programas voltados para os temas da inclusão, da diversidade, dos direitos humanos e da sustentabilidade foram criados a partir do governo Lula, correspondendo a $21,2 \%$ do total. Outro conjunto de programas criados nesse período são aqueles voltados para formação dos profissionais das escolas e dos órgãos gestores da educação municipal, correspondendo a 11 programas, que representam $33,3 \%$ dos programas criados nesse período. Além desses dois grupos, todos aqueles

${ }^{5}$ Cf Lei no 8.913, de 27 de julho de 1994 (PNAE); Lei no 10.880, de 9 de junho de 2004 (PNATE e EJA); Lei $n^{\circ} 11.947$, de 16 de junho de 2009 (PDDE); Lei $n^{\circ} 12.306$, de 6 de agosto de 2010 (Ensino Médio) 
voltados para a educação infantil $(n=3)$ e para o ensino médio $(n=2)$ também foram criados nesse período.

Até 2003, a principal forma de adesão aos programas ou outras ações de assistência técnica e financeira da União era a apresentação de PTA (Plano de Trabalho Anual) ${ }^{6}$ em conformidade com os critérios e prazos estabelecidos em editais publicados pelo FNDE. Os PTAs eram avaliados e, se aprovados, davam origem a convênios. A partir de 2004, essa forma foi, gradativamente, substituída por outros procedimentos.

A partir de 2007, todos os programas passaram a ter como referência o PDE (Plano de Desenvolvimento da Educação), que reestruturou as transferências voluntárias sob uma visão sistêmica e introduziu a priorização de municípios e escolas no âmbito de alguns programas com base no Índice de Desenvolvimento da Educação Básica (IDEB) ${ }^{7}$.

Com a instituição do PDE, o apoio técnico e financeiro do Ministério da Educação aos entes federados ficou condicionado à adesão dos mesmos ao Plano de Metas Compromisso Todos pela Educação e à elaboração do Plano de Ações Articuladas (PAR), conforme se pode constatar na Lei que regulamentou tal plano:

Art. $1^{\circ}$. O apoio técnico ou financeiro prestado em caráter suplementar e voluntário pela União às redes públicas de educação básica dos Estados, do Distrito Federal e dos Municípios será feito mediante a pactuação de Plano de Ações Articuladas - PAR.

$\S 1^{\circ}$ A transferência direta prevista no caput será executada pelo Fundo Nacional de Desenvolvimento da Educação - FNDE e ficará condicionada ao cumprimento de termo de compromisso, que deverá conter, no mínimo: I - identificação e delimitação das ações a serem financiadas; II - metas quantitativas; III cronograma de execução físico-financeira; IV - previsão de início e fim da execução das ações e da conclusão das etapas ou fases programadas. (BRASIL, 2012)

\footnotetext{
${ }^{6}$ Plano de Trabalho Anual é a nomenclatura utilizada pelo MEC/FNDE para o modelo de formulário padrão dessa autarquia a ser preenchido pelos governos subnacionais para a solicitação de recursos para ações específicas, determinados, em geral, por resoluções. Informações sobre os procedimentos das transferências por meio de PTAs podem ser obtidas em Cruz, 2009.

${ }^{7} \mathrm{O}$ IDEB é um indicador nacional da qualidade da educação, calculado pelo INEP (Instituto Nacional de Estudos e Pesquisas Educacionais Anísio Teixeira), a partir de dois componentes: a taxa de rendimento escolar (aprovação) e as médias de desempenho nos exames aplicados pelo Inep. (Fonte: http://portal.mec.gov.br)
} 
Assim, após a adesão dos entes subnacionais ao Plano de Metas intitulado "Compromisso Todos pela Educação", os estados e municípios brasileiros foram mobilizados para a elaboração de seu PAR, para um período de quatro anos, com base em um modelo de Plano previamente estruturado pelo MEC em quatro eixos temáticos: I- Gestão Educacional; II - Formação de Professores e dos Profissionais de Serviço e Apoio Escolar; III - Práticas Pedagógicas e Avaliação; IV - Infraestrutura Física e Recursos Pedagógicos. A partir de tais eixos, o modelo de plano foi constituído de três componentes: a) Diagnóstico do Contexto Educacional; b) Ações a serem implementadas e os respectivos resultados esperados; c) Metas a atingir para o desenvolvimento do IDEB (BRASIL, 2007b). No caso dos 1.242 Municípios priorizados, o FNDE disponibilizou ainda um instrumento de diagnóstico do contexto educacional de cada um e assessoria técnica in loco para garantir a elaboração do PAR.

A partir de 2007, observa-se que novos programas são instituídos e antigos são reconfigurados ou têm suas metas redefinidas para atender à política do PDE/PAR, de forma que, cada vez mais, os programas passam a focar grupos de municípios e de escolas, conforme diagnósticos dos municípios feitos pelo MEC/INEP para o PAR. Essas medidas ficam mais claras nas diretrizes e instrumentos fornecidos para a segunda versão do PAR.

Para a elaboração da segunda versão do PAR, referente ao quatriênio 2011-2014, o MEC disponibilizou aos entes subnacionais quatro instrumentos que deveriam orientar a construção do referido plano: (a) Indicadores Demográficos e Educacionais (IDE), que consiste em um conjunto de tabelas com dados demográficos e educacionais para cada município, estado e Distrito Federal; (b) Instrumento de Diagnóstico, que consiste em um questionário, organizado em quatro dimensões (gestão educacional, formação de professores e dos profissionais de serviço e apoio escolar, práticas pedagógicas e avaliação, infraestrutura física e recursos pedagógicos), destinado a coletar informações quantitativas e qualitativas sobre o sistema de educação de cada unidade da federação; (c) Manual de elaboração do PAR, que fornece orientações sobre os procedimentos para sua elaboração e; (d) Guia prático de ações do PAR, que consiste em um "menu" de programas e ações de assistência técnica e financeira que podem ser solicitados pelo ente, conforme dimensões, indicadores e situação educacional do ente indicada em cada item do diagnóstico.

O "guia prático de ações para Municípios" do PAR 2011-2014 vincula os programas e projetos de transferência voluntária do MEC/FNDE a cada área 
e dimensão do PAR. Assim, por exemplo, para a dimensão Gestão Educacional são ofertados os programas Pró-Conselho, o LSE (Levantamento da Situação Escolar), o PRADIME, entre outros. Para a dimensão formação de professores e de profissionais de serviço e apoio escolar são ofertados, entre outros, o Programa Nacional Escola de Gestores, o Pró-letramento, o Prófuncionário. (BRASIL, 2011).

Quanto ao segundo aspecto, a análise das resoluções ao longo do período estudado permitiu a identificação de três formas principais de adesão dos governos subnacionais aos programas de assistência técnica e financeira do $\mathrm{MEC} / \mathrm{FNDE}$.

1) Programas universais, que atendem a todos os entes subnacionais, sem necessidade de apresentação de projetos ou assinatura de termos de adesão ou compromisso. Tais programas têm valores e critérios definidos nacionalmente e, por tal condição, suas transferências são feitas de forma automática. Todos os programas de transferências legais se incluem nesta categoria.

2) Programas que exigem apenas a assinatura de termo de adesão ou de compromisso ou cadastramento em sistemas eletrônicos do MEC, a exemplo do Sistema Integrado de Monitoramento, Execução e Controle (SIMEC). Esta forma de adesão foi se expandindo após a instituição do Plano de Desenvolvimento da Educação (PDE), quando vai ocorrendo, gradativamente, a substituição das transferências voluntárias por meio de convênios por transferências organizadas por meio de programas. No período de 2004 a 2007, do total de 178 resoluções do FNDE que regulamentaram as transferências para os entes subnacionais, $33,7 \%$ faziam referência à necessidade de apresentação de projeto ou planos para o ente ser contemplado com recursos dos programas, envolvendo um total de 18 programas. Após a implantação do PDE, no período de 2008 a 2014, de um total de 303 resoluções analisadas, apenas 5,9\% fizeram tal exigência, passando a ser exigida apenas a assinatura de termo de adesão ou de compromisso ou apenas a manifestação no PAR ou ainda o cadastro do ente governamental nos sistemas eletrônicos do MEC. Isto ocorreu porque o governo federal (MEC/FNDE) passou a estruturar a maioria dos programas, definindo suas ações de forma mais detalhada e a selecionar previamente os beneficiários da ação, em conformidade com os indicadores educacionais e metas estabelecidos no "Plano de Metas Compromisso Todos pela Educação"

3) Programas que exigem apresentação de projeto ou planos para a adesão. Esta que até 2003, constituía a principal forma de adesão aos 
programas de assistência técnica e financeira, foi diminuindo, conforme já explicado, de forma que atualmente constitui a forma menos presente. Neste grupo, identificamos duas situações: (a) aqueles programas que estão abertos a todos os entes, sendo a forma de acessar seus recursos, a apresentação de um projeto ou plano, conforme estabelecido na resolução, a exemplo do Programa Brasil Alfabetizado $(\mathrm{PBA})^{8}$ e do Programa de recuperação de rede física escolar; (b) aqueles cujos beneficiários são selecionados previamente, mas sendo necessária a apresentação do projeto, em conformidade com as diretrizes estabelecidas pelas resoluções do FNDE, para serem atendidos. Nesse grupo, incluem-se o Proinfantil, o Programa Ensino Médio Inovador (ProEMI), o Programa Mais Cultura na Escola, o Programa Mais Educação e o Projovem. Porém, cabe ressaltar que, com exceção deste último, em todos os outros programas os projetos são "elaborados" por meio de formulários eletrônicos do MEC, consistindo apenas em fornecimento de informações de caráter técnico.

Quanto à forma de transferência, observa-se que, a partir de 2007, ocorre também uma grande diversidade de procedimentos. Considerando apenas os programas e as normas em vigência e aqueles que envolvem transferências, identificaram-se quatro formas principais em torno das quais os programas podem ser agrupados ${ }^{9}$ :

a) Programas cujos recursos são transferidos para os governos estaduais, distrital e municipais, por meio das prefeituras e/ou secretarias de educação. Nesse grupo há um total de 10 programas: o PNATE, o PNAE, o PBA, o Programa Especial de Recuperação da Rede Física Escolar Pública, o ProInfância, o Programa Caminho da Escola, o PRONATEC, o Programa Brasil Profissionalizado, o Programa Especial de Fortalecimento do Ensino Médio e o Programa de Apoio à Creche - Brasil Carinhoso.

b) Programas cujos recursos são transferidos diretamente para as escolas. Esta forma de transferência começou com o PDDE e o PDE-Escola e foi gradativamente expandida, sobretudo após 2007 , de modo que atualmente,

\footnotetext{
${ }^{8}$ No caso específico do PBA, até 2007 , era exigida apenas a assinatura do termo de adesão, mas a partir de 2008, passou a ser exigida também a elaboração do PPAlfa.

9 Alguns dos programas podem integrar mais de um grupo, pois o critério utilizado para o agrupamento não é excludente, uma vez que o nosso interesse de agrupamento é mostrar a diversidade de mecanismos de transferências na política de assistência técnica e financeira da União para a educação básica. Assim, alguns programas têm mais de uma forma de realizar suas transferências.
} 
engloba um total de 8 programas/ações. Além dos dois já citados, integram este grupo o Programa Mais Educação, o ProEMI, o Programa Mais Cultura nas Escolas, o Programa Escola Acessível, o Programa Nacional de Educação Ambiental e o Programa Atleta na Escola.

c) Programas cujos recursos são transferidos para as Instituições de Ensino Superior, principalmente, federais, para que estas prestem os serviços para os sistemas de ensino estadual, distrital e municipal. Em geral, são programas voltados para formação continuada dos profissionais de educação e para a produção de material didático. Nesse grupo encontram-se 14 programas: PRADIME, Pró-Conselho, Programa Escola de Gestores, Pro-Infantil, Programa Nacional de Tecnologia Educacional, Programa Saúde na Escola; Projeto Escola que Protege, Programa Saberes Indígenas nas Escolas, Pacto Nacional pelo Fortalecimento do Ensino Médio, Programa Escola da Terra, o Programa Gestão da Aprendizagem Escolar, Pró-funcionário, Olimpíadas Escolares, Pacto Nacional pela alfabetização na Idade Certa. Tais programas combinam transferências para IES e pagamento de bolsas diretamente aos profissionais envolvidos nas ações (coordenadores, formadores, tutores, entre outros), ou seja, tais recursos são executados diretamente pelo FNDE.

d) Programas cuja transferência envolve mais de um beneficiário, em geral governos, escolas, IES. Neste grupo estão 05 programas: Projovem, Programa Mais Educação, Escola que Protege, Programa Territórios Etnoeducacionais, PRONACAMPO. Tais programas envolvem mais de um beneficiário pelo fato de terem ações desenvolvidas por instituições diferentes, em geral, sendo as ações de formação e de elaboração de material didático executadas pelas universidades e as demais pelos governos e/ou escolas.

Em relação à coordenação federativa, identificamos três tipos de instâncias voltadas para ação conjunta dos entes federados no âmbito da assistência técnica e financeira da União para a educação básica.

O primeiro tipo apresenta características de tomada de decisão conjunta pelos entes federados, envolvendo tanto a dimensão de policy decision quanto a dimensão de policy making, e comportam duas instâncias: uma vinculada ao Fundeb - a Comissão Intergovernamental de Financiamento para a Educação Básica de Qualidade (CIFEBQ); e outra vinculada aos Programas Brasil Alfabetizado e de Apoio aos Sistemas de Ensino para atendimento à Educação de Jovens e Adultos - a Comissão Nacional de Alfabetização e Educação de Jovens e Adultos (Cnaeja). 
O segundo e terceiro tipos de instâncias, embora integrem representação das três esferas governamentais, não apresentam características de tomada de decisão conjunta, atuando mais na esfera do policy making, ou seja, essas instâncias assumem mais o papel de pactuação, articulação, mobilização e controle social, de forma que a maioria delas assume a estrutura de rede. São elas: o Conselho de Acompanhamento e Controle Social do Fundo de Manutenção e Desenvolvimento da Educação Básica e de Valorização dos Profissionais da Educação no âmbito da União, o Comitê Estratégico do PAR, a Rede de Parcerias do Programa Nacional de Formação Continuada a Distância nas Ações do FNDE (Formação pela Escola), o Comitê Gestor Nacional do Pacto Nacional pelo Fortalecimento do Ensino Médio e o Comitê Gestor Nacional do Pacto Nacional pela Alfabetização na Idade Certa.

Assim, se tomamos coordenação federativa como processo de tomada de decisão conjunta, pode-se afirmar que esta tem ficado restrita ao Fundeb e às ações de Educação de Jovens e Adultos. Considerando a grande quantidade de programas e ainda o fato de não existir no FNDE uma instância de coordenação federativa geral, conclui-se que, embora tenham ocorrido avanços na tomada de decisão conjunta em relação às práticas que prevaleceram antes de 2007, estes estão limitados a poucas ações.

Se o avanço nos processos de coordenação federativa na ação de assistência técnica e financeira da União foram tímidos, a regulamentação dessas ações avançou na mesma medida em que se diversificaram os programas e incorporam mecanismos mais redistributivos. A partir de uma escala de nível de regulamentação de 0 a 10 , considerados todos os três componentes da tipologia da regulamentação (aspectos relativos à distribuição dos recursos, aspectos técnico-burocráticos e aspectos político-pedagógicos), observou-se que a maioria dos programas ficou igual ou acima da pontuação média da escala. Considerado os aspectos financeiros e burocráticos, a maioria dos programas também obteve pontuação igual ou superior à média. Nos aspectos político-pedagógicos, $21 \%$ dos programas apresentaram pontuação igual ou superior à média na escala de regulamentação. Embora este grupo apresente percentual menor, cabe considerar que seus componentes se referem a funções que, em sua maioria, são do campo específico de autonomia dos governos subnacionais.

Os dados apresentados nesta seção evidenciam que a diversificação de programas, ocorrida a partir de 2004, foi acompanhada da diversificação de formas de adesão e de formas de operacionalizar as transferências de recursos 
de tais programas, incorporando, consequentemente, uma diversidade de atores institucionais na operacionalização das ações de assistência da União para a educação básica, para além das prefeituras e das secretarias de educação. Esses novos arranjos de transferência dos recursos possibilitam a inferência de que estes constituem mecanismos de indução para a garantia de implementação das políticas em conformidade com os seus desenhos.

A análise mostra ainda que são os Programas de Assistência Voluntária, sobre os quais o MEC possui discricionariedade, que mais introduzem a lógica da política educacional esboçada pelo MEC/FNDE. Isto fica evidente pela diversificação e complementariedade dos programas que abarcam um amplo leque de níveis, modalidades, áreas e dimensões da educação básica, tais como educação infantil, EJA, educação especial, infraestrutura, currículo, formação de professores e muitos outros temas.

\section{TENSÕES ENTRE AUTONOMIA E INTERDEPENDÊNCIA NA ASSISTÊNCIA DA UNIÃO PARA A EDUCAÇ̃̃o BÁSICA}

Tomando-se a perspectiva analítica de Arretche $(2004,2012)$ sobre o desenho das políticas educacionais e de Tsebelis (1995) sobre veto players, analisa-se a regulamentação da assistência técnica e financeira da União quanto à autonomia dos entes federados. Os dados apresentados, em seu conjunto, fornecem evidências de que o desenho das políticas de assistência técnica e financeira do MEC/FNDE tem, cada vez mais, incorporado mecanismos de indução e controle. A análise do conteúdo das resoluções e dos manuais de assistência técnica e financeira do MEC mostrou que o MEC lança mão de diversos recursos e mecanismos para influenciar a agenda educacional dos governos subnacionais e induzir a implementação de políticas na direção estabelecida pelo governo central. A partir de 2004 e, sobretudo, a partir de 2007, o governo federal aumentou sua capacidade de influência da agenda educacional dos governos subnacionais, por meio das transferências para a educação básica. Isto foi garantido por meio de três mecanismos principais.

O primeiro mecanismo envolve a alteração do desenho das políticas de assistência técnica e financeira. Arretche (2004, p.22), ao analisar os mecanismos e processos que tornam possível coordenar ações entre esferas de governo nas políticas de saúde, indica que esta capacidade é diretamente afetada pelo modo como estão estruturadas as relações federativas no desenho das políticas particulares. No campo da educação, a análise da regulamentação das transferências do MEC corrobora esse argumento. 
O novo desenho das políticas de assistência técnica e financeira da União que se iniciou em 2004 e teve seu ponto máximo em 2007, com a implantação do Plano de Desenvolvimento da Educação (PDE), incorporou um conjunto de medidas estratégicas que possibilitaram maior poder de influência da agenda educacional dos governos subnacionais, tais como:

a) a organização da assistência técnica e financeira, preferencialmente por meio de programas formatados nacionalmente, mas, ao mesmo tempo, incorporando componentes de diversidade, tanto em seus objetos quanto em seus procedimentos de transferência de recursos;

b) regulamentação da assistência técnica e financeira para além de seus aspectos técnico-burocráticos, incorporando princípios e arranjos político-pedagógicos, de forma que os programas passaram a se constituir mais que veículos de transferência de recursos, mas também (quiçá principalmente) mecanismos de introdução de políticas de educação básica elaborados pelo governo federal nos sistemas estaduais e municipais de educação;

c) orientação do planejamento global dos sistemas estaduais e municipais de educação por meio do PAR, vinculado a parâmetros de avaliação dos sistemas educacionais, por meio do IDEB e, consequentemente vinculando as metas do IDEB e a elaboração do PAR ao recebimento de recursos da assistência técnica e financeira voluntária do MEC, por meio de assinatura do Termo de Compromisso Todos pela Educação; e

d) a priorização de grupos de municípios como beneficiários de determinadas políticas incidentes sobre seus indicadores educacionais.

Esses mecanismos têm aumentado a capacidade de coordenação federal das ações de governo por conta, principalmente, de suas complementaridades, de forma que cada mecanismo incide sobre determinados aspectos da agenda educacional e das relações federativas, indo do nível mais macro (do planejamento da política municipal/estadual de educação) ao nível mais micro (do formato das ações a serem implementadas pelas escolas). 
No seu conjunto, esse modelo implica em maior influência da União na agenda educacional dos entes subnacionais, sendo os programas de transferências voluntárias os que mais apresentam potencial para tal, pois estes são os mais regulamentados, em especial em seus componentes políticopedagógicos. Também foram os que mais demostraram alterações em seus formatos conforme a agenda do governo federal.

Em segundo lugar, o governo aumentou também seu poder de influência sobre a agenda educacional dos governos subnacionais, mobilizando recursos e construindo mecanismos para diminuir a possibilidade da ação de veto players, bem como as instâncias de negociação e de mediação de suas políticas de assistência financeira.

As transferências legais e voluntárias regulamentadas por meio de resoluções do executivo federal constituem mecanismos eficazes de implementação de políticas educacionais, entre outras razões, porque coíbem veto players próprios do regime federativo. Tsebelis (1995), em sua teoria do veto player, explicita que o governo pode escolher procedimentos de política voltados para reduzir o número de veto players envolvidos e as dimensões de negociações, já que a estabilidade das políticas diminui quando o tamanho do yolk $k^{10}$ de cada um desses atores aumenta.

Tomando a abordagem teórica do referido autor, pode-se analisar que, no caso em estudo, o governo federal, por meio de cada política específica, controla as arenas de negociações. Assim, ao direcionar as transferências a título de assistência financeira aos governos subnacionais para determinados fins, conforme sua agenda, consegue implementar as políticas de seus interesses, anulando veto players que poderiam se apresentar caso essas mesmas políticas fossem implementadas por outras vias e em outras arenas, nas quais o tamanho do yolk fosse maior e a estabilidade da política fosse ameaçada. Além disso, por meio desses mecanismos, aumenta também sua possibilidade de garantir consensos mesmo nas políticas que exigem arenas de

\footnotetext{
10 Yolk é um conceito da teoria da escolha pública, utilizado por Tsebelis, para determinar o raio de ação de todos os atores em uma política comum, podendo ser tanto uma área de congruência como de divergência.
} 
negociações mais amplas e que dependem de veto players institucionais, a exemplo das leis do Fundeb, do Piso Profissional Salarial Nacional e do PNE.

Um desses mecanismos tem sido a regulamentação das transferências legais e voluntárias pelo FNDE, autarquia do MEC responsável pelas transferências dos recursos financeiros da União a título de assistência financeira, sem a participação efetiva dos demais entes federados, indicando uma definição unilateral, pela União, dos critérios e procedimentos de tais transferências, já que não há no interior do FNDE nenhuma instância de coordenação federativa. Isto implica um deslocamento da arena principal de formulação das políticas educativas (o parlamento e o Ministério da Educação) para uma arena mais insulada ao controle social e a veto players. Assim, o FNDE vai se consolidando como órgão formulador da política nacional de educação no "varejo", visto que, conforme mostrado, a regulamentação das transferências introduz princípios, regras, modelos, lógicas de ação e estabelece prioridades, delineando uma política educacional de âmbito nacional.

Outros dois mecanismos têm cumprido a função de diminuir ou eliminar arenas de negociação ou veto player. São eles: a anulação gradativa dos governos estaduais como mediadores dos programas e das ações de assistência financeira do MEC, que passaram a ser acordadas diretamente com os governos municipais; e o direcionamento de algumas políticas e recursos diretamente para as escolas, eliminando também a mediação dos órgãos gestores do sistema municipal e estadual de educação. Evidência disto é o fato de que o PDDE (Programa Dinheiro Direto nas Escolas) foi o programa que mais cresceu em recurso e mais se diversificou ao longo do período estudado. Assim, o MEC/FNDE aumenta as chances de que a política chegue às escolas conforme inicialmente desenhada.

Essa perspectiva teórica abre caminho para a análise do terceiro mecanismo utilizado para influenciar a agenda educacional dos governos subnacionais, que é a obtenção de consenso junto a atores fundamentais. Arretche $(2004,2012)$ defende que o desenho que se imprime a cada política específica é importante para a influência da agenda dos governos subnacionais. Mas ainda assim, sempre há a possibilidade de determinados atores não aderirem ao desenho proposto, tornando necessário o uso de mecanismos complementares. 
Nesse sentido, um argumento da teoria de Tsebelis (1995), ainda que voltada para uma análise mais macro da política dos governos nacionais, é pertinente para esta análise. De acordo com o autor existem múltiplos veto players, e estes atuam em arenas diversificadas (nas câmaras, nos partidos, nos órgãos formuladores das políticas e em outras instituições importantes, como sindicatos, organizações patronais). Assim, para algumas políticas, o consenso pode ser obtido mais eficazmente junto a um ator institucional chave, que poderia se constituir em poderoso veto player ou que poderia influenciar outros veto players a aderirem à política proposta. Ainda de acordo com o autor citado, tal consenso se faz por meio de compromissos prévios, reduzindo as dimensões de negociações.

Os dados evidenciam que o MEC aumentou seu poder de indução da agenda educacional dos governos subnacionais também pela mobilização de recursos políticos para obtenção de consenso junto a atores chaves, como a UNDIME e a UNCME. O consenso foi obtido tanto pela negociação prévia de políticas com essas entidades quanto pela via de transferências de recursos livres de regulamentação para essas entidades que, enquanto representantes de atores que atuam nos sistemas municipais de educação, têm um grande poder de convencimento e de alinhamento do discurso de suas bases. Constatou-se no sistema SIGEFWEB do FNDE, no período analisado, repasses que totalizaram R $\$ 27.325 .169,09$ para a UNDIME, sendo desse total R\$ $722.911,11$ destinados às unidades regionais da entidade nos estados do Rio Grande do Norte (R\$ 80.855,28) no ano de 2005, de Pernambuco $(\mathrm{R} \$ 309.524,73)$ e de Mato Grosso ( $\mathrm{R} \$ 332.531,10)$, no ano de 2006. Para a UNCME, foi identificado um repasse no valor de $\mathrm{R} \$ 647.816,60$ e para o CONSED, também um repasse no valor de $\mathrm{R} \$ 500.000,00$, ambos no ano de 2006. Aguiar (2002) mostra que essa mesma estratégia foi utilizada pelo MEC durante o governo FHC, porém, escolhendo outro ator estratégico como sua base de apoio - o CONSED.

Considerando-se os dados apresentados, a análise procedida aponta que a regulamentação da assistência técnica e financeira da União tende para um modelo de cooperação induzida e de dependência, uma vez que os dados apresentados sobre a coordenação federativa indicaram limitadas instâncias para o compartilhamento de tomada de decisões nesse campo. Em contrapartida, foram encontradas diversas evidências de que a União induz a agenda dos governos subnacionais que a ela aderem muito mais por condições 
de dependência do que pelo exercício de sua autonomia. Em processos de transferências intergovernamentais marcados por excessiva normatização do governo central e elevado grau de dependência financeira e institucional dos governos subnacionais, o ente tem sua autonomia limitada e torna-se um mero agente administrativo, característica mais própria de um federalismo coercitivo do que de um federalismo cooperativo.

Embora o modelo de assistência financeira da União para a educação básica tenha incorporado princípios e mecanismos na perspectiva da correção das desigualdades e do estabelecimento de padrões mínimos nacionais, a regulamentação dessas transferências aponta diversos limites nessa direção, pois não tem incorporado mecanismos capazes de garantir flexibilidade para a tomada de decisão do ente contemplado e, principalmente, de influenciar as prioridades locais e de lidar com as deficiências de infraestrutura, de forma a aumentar a capacidade político-administrativa dos entes nas regiões mais pobres para propor e gestar as políticas públicas de educação.

\section{CONSIDERAÇÕES FINAIS}

Compreendendo que as tensões federativas se originam na complexidade que envolve a combinação de autonomia e interdependência nas federações, que conduzem a organização de diferentes arranjos na repartição de competências entre os entes federados, a ação de assistência técnica e financeira da União, ao incorporar diversos arranjos para influenciar a agenda educacional dos governos subnacionais, torna-se objeto de tensões federativas.

Os dados apresentados evidenciam que o atual modelo de assistência técnica e financeira da União torna mais acentuadas as tensões federativas no campo do financiamento da educação básica. Estas envolvem tanto o desenho da política de assistência técnica e financeira quanto a sua operacionalização, mediante a diversa e desigual realidade educacional e político-administrativa das unidades federativas brasileiras. Nesses termos, as tensões envolvem tanto a relação entre a ação da assistência técnica e financeira da União e os princípios de qualidade e equidade a ela associados, quanto a relação entre a capacidade decisória da União e a autonomia dos entes federados subnacionais para formular e implementar políticas educacionais.

A CF/1988, por um lado, deu prerrogativas para a União prestar assistência técnica e financeira aos estados e municípios com autoridade decisória sobre o desenho dessas políticas. Por outro, associou essa ação ao alcance da qualidade e da equidade na educação básica. Esse vínculo introduz 
uma primeira tensão, que envolve a necessidade de políticas de assistência que incorporem ao mesmo tempo elementos de equidade e qualidade, já que, dessa forma, não é possível garantir a equidade sem a garantia da qualidade para todos, de modo que a simples redistribuição de recursos disponíveis se torna insuficiente para tal.

Consequentemente, o alcance da equidade, vinculado a um padrão mínimo de qualidade em todo o território nacional, não pode ser confundido com tratamento padronizado de todas as unidades, tendo em vista as diferentes situações em que elas se encontram. Nesse caso, os mecanismos de incentivo seletivos se tornam, de fato, necessários, já que a garantia de equidade exige tratamento discriminatório conforme as assimetrias entre regiões, estados e indivíduos, introduzindo uma tensão entre unidade e diversidade na assistência da União.

Tendo em vista que, no Brasil as desigualdades territoriais também estão associadas a pouca capacidade administrativa, estruturas clientelistas e baixo grau de democracia e de accoutability nas diferentes jusidições da federação brasileira, os mecanimos de incentivo seletivo podem tanto ser portadores de condicionalidades e de mecanismos de controle como também se consituírem em incentivos para a dependência dos governos estaduais de assistência federal, como pensado pelos adeptos do federalismo competitivo. Assim, estabelece-se uma outra tensão na assistência da União, entre a sua regulamentação por parte do executivo federal e a autonomia dos entes federados subnacionais para formular e implementar suas políticas de educação. Embora os estados e municípios tenham autonomia, que deve funcionar como um contrapeso, no plano local, à concentração de autoridade na União, inclusive, não aderindo às políticas propostas pelo governo federal, o exercício dessa autonomia depende tanto de suas capacidades fiscais e político-administrativas quanto do desenho que o governo federal imprime às políticas e assistência técnica e financeira.

Neste caso, observou-se que os recursos financeiros e institucionais dos governos subnacionais, sobretudo, dos municípios, são bastante limitados, enquanto os recursos institucionais que a União mobilizou na sua ação de assistência técnica e financeira mostraram um grande potencial para influenciar a agenda educacional dos governos subnacionais. Assim, o nível de influência da agenda educacional dos governos subnacionais por meio da assistência técnica e financeira é resultante da combinação dessas duas dimensões: pouca capacidade fiscal e político-administrativa da maioria dos 
municípios para formular e implementar políticas educacionais e do desenho das políticas de assistência financeira adotado a partir de 2004. Desse modo, estabelece-se, de fato, um paradoxo federativo envolvendo a coordenação das políticas nacionais, a autonomia e a forte dependência dos entes subnacionais, sobretudo, dos municípios mais dependentes dessa assistência financeira.

No âmbito dos programas de assistência, a combinação de um alto nível de regulamentação, atribuições de cunho técnico gerencial aos governos subnacionais na implementação das políticas, limitadas instâncias de coordenação federativa, definição das diretrizes e da forma de planejamento da política educacional dos entes federados subnacionais (PAR) e a organização de programas diversificados e desenhados em suas ações e formas de execução, indicam a constituição de uma política federal de educação básica assumida como uma política nacional. Isto porque, principalmente, os programas de assistência voluntária induzem modelos de políticas a serem implementados pelos sistemas de ensino dos governos subnacionais.

Para os governos subnacionais que dispõem de limitados recursos financeiros, técnicos e políticos, uma política de educação básica proposta e desenhada pelo governo federal implica em ter alguma referência de política; para os governos subnacionais que apresentam maiores condições de formular e implementar suas políticas educacionais, ainda que com limitações financeiras, uma política federal de educação básica, implica em limitações ao exercício de sua autonomia. Assim, a assistência técnica e financeira da União aos entes federados subnacionais na oferta e manutenção da educação básica vem se desenvolvendo em meio a tensões entre necessidades da nação, interesses do governo federal e interesses e necessidades dos governos subnacionais.

\section{REFERÊNCIAS}

ARAÚJO, Raimundo Luiz Silva. O federalismo, os fundos na educação e a diminuição das desigualdades. Revista Retratos da Escola. Brasília, v. 6, n. 10, p. 49-63, jan./jun. 2012. Disponível em: <http//www.esforce.org.br>. Acesso em: 11 nov. 2013.

ARAÚJO, Raimundo Luiz Silva. Limites e possibilidades da redução das desigualdades territoriais por meio do financiamento da educação básica. 2013. 416 f. Tese (Doutorado em Educação). 
ARRETCHE. Federalismo e políticas sociais no Brasil: problemas de coordenação e autonomia. São Paulo em perspectiva, São Paulo, v.18, n. 2, p.17-26, 2004. Disponível em: < http://www.scielo.br/scielo.php?pid=S010288392004000200003\&script=sci_abstract $>$. Acesso em 24 mai. 2014.

- Quem taxa e quem gasta: a barganha federativa na federação brasileira. Revista Sociologia e Politica, Curitiba, n. 24, p. 69-85, jun. 2005.

Democracia, federalismo e centralização. Rio de Janeiro: Editora

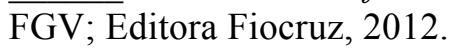

BIELA, Jan. ANNIKA, Hennl. KAISER, André. Policy making in multilevel systems: federalism, decentralisation, and performance in the OECD countries. Colchester, UK: ECPR Press. University of Essex, 2013.

BRASIL. Constituição da República Federativa de 1988. Brasília, DF, Presidência da República, 1988. Disponível em: < http://www.planalto.gov.br/ccivil_03/Constituicao/Constituicao.htm>. Acesso em: 05 abr. 2012.

Lei $n^{\circ}$ 9.394/96 de 20 de dezembro de 1996. Estabelece as Diretrizes e Bases da Educação Nacional. Brasília, DF, 20 dez, 1996. Disponível em: $<$ http://www.planalto.gov.br/ccivil_03/ leis/19394.htm>. Acesso em: 05 mai. 2013.

Plano de desenvolvimento em Educação: razões, princípios e programas. Brasília, DF, MEC: 2007a.

. Resolução CD/FNDE $n^{\circ} 29$, de 20 de julho de 2007. Estabelece os critérios, os parâmetros e os procedimentos para a operacionalização da assistência financeira suplementar e voluntária a projetos educacionais, no âmbito do Compromisso Todos pela Educação, no exercício de 2007. Brasília, 2007b.

Conferência Nacional de Educação (CONAE) 2010: Construindo o Sistema Nacional Articulado de Educação: Plano Nacional de Educação, diretrizes e estratégias; Documento Final. Brasília, DF: MEC, 2010. Disponível em: <http://conae.mec.gov.br/ images/.stories/pdf pdf/documetos/ documento_final.pdf $>$. Acesso em: 16 maio. 2012. 
. Plano de Ações Articuladas - PAR 2011 - 2014: Guia prático de ações para Municípios. Brasília, DF: Ministério da Educação, 2011.

Lei $n^{\circ} 12.695$ de 25 de julho de 2012. Dispõe sobre o apoio técnico ou financeiro da União no âmbito do Plano de Ações Articuladas; altera a Lei $\mathrm{n}$-11.947, de 16 de junho de 2009, para incluir os polos presenciais do sistema Universidade Aberta do Brasil na assistência financeira do Programa Dinheiro Direto na Escola; altera a Lei $\mathrm{n}^{\mathrm{o}} 11.494$, de 20 de junho de 2007, para contemplar com recursos do FUNDEB as instituições comunitárias que atuam na educação do campo; altera a Lei $\mathrm{n}^{-} \mathrm{10.880}$, de 9 de junho de 2004, para dispor sobre a assistência financeira da União no âmbito do Programa de Apoio aos Sistemas de Ensino para Atendimento à Educação de Jovens e Adultos; altera a Lei no 8.405, de 9 de janeiro de 1992; e dá outras providências. Brasília, DF, 25 jul. 2012. Disponível em: $<$ http://www.planalto.gov.br/ccivil_03/_Ato2011-2014/2012/Lei/

L12695.htm>. Acesso em: 06 out. 2013.

Lei $n^{\circ} 13.005$, de 25 de junho de 2014. Aprova o Plano Nacional de Educação PNE e dá outras providências. Brasília, DF, 25 Jun. 2014a. Disponível em: <http://www.planalto.gov.br/ccivil_03/ _Ato20112014/2014/Lei/L13005.htm>. Acesso em: 17 mar. 2015.

ELAZAR, Daniel. J. Exploring federalism. Alabama: The University of Alabama Press, 1991.

MARTINS, Paulo de Sena. O financiamento da educação básica por meio de fundos contábeis: estratégia política para a equidade, a autonomia e o regime de colaboração entre os entes federados. 2009. 338 f. Tese (Doutorado em Educação) - Programa de Pós-graduação em educação, Universidade de Brasília, Brasília, 2009.

PINTO, José Marcelino Rezende. Financiamento da educação básica: a divisão de responsabilidades. Revista Retratos da Escola. Brasília, v. 6, n. 10, p. 105117, jan./jun. 2012. Disponível em: <http//www.esforce.org.br >. Acesso em: 03 mai. 2013.

A política recente de fundos para o financiamento da educação e seus efeitos no pacto federativo. Educ. Soc., Campinas, v. 28, n. 100 - Especial, p. 877-897, out. 2007. Disponível em <http://www.cedes.unicamp.br>. Acesso em 15 set. 2012. 
O FUNDEB na perspectiva do custo aluno qualidade. Em Aberto. Brasília, v.28, n.93, p. 101-118, jan./jun. 2015.

WATTS, Ronald. Comparing federal systems. Montreal: McGill-Queen's University Press, 2008.

TSEBELIS, George. Decision making in political systems: veto players in presidentialism, parlamentarism, multicameralism and multipartyism. British Journal of Political Science. Londres, v. 25, n.3, p.289-325, 1995.

Recebido em 15/12/2016

Aprovado em 30/03/2017 